\title{
Die Voorkomsfrekwensie van Oor- en Gehoorpatologie by Kinders in die Afgesonderde Gemeenskap van Tshikunda - Malema
}

\author{
Santie Meyer M(Log)(Pret.) \\ Carlin van den Berg B(Log)(Pret.) \\ Departement Spraakheelkunde en Oudiologie \\ Universiteit van Pretoria
}

\begin{abstract}
OPSOMMING
Hierdie navorsing het ten doel die bepaling van die aard en voorkoms van oor- en gehoorpatalogie by ' $n$ afgesonderde gemeenskap in $V$ Venda. Honderd drie-en-vyftig kinders is aan 'n siftingsprosedure wat uit 'n oor-, neus- en keelondersoek, impedans- en suiwertoonsiftingsoudiometrie bestaan, onderwerp. Uit die resultate blyk dit dat 15,2\% van die getoetste populasie oor- en gehoorprobleme het. Die patologie wissel van middeloorpatologie $(13,4 \%)$ tot sensories-neurale patologie $(1,8 \%)$. Dit wil dus voorkom asof die voorkoms van oor-en gehoorprobleme onder hierdie bevolking relatief laag is. Dit bevestig vorige navorsing wat bevind dat die algemene gesondheid van hierdie bevolking goed is.
\end{abstract}

\section{ABSTRACT}

The aim of this research was to determine the incidence of ear and hearing pathology in an isolated community in Venda. One hundred and fifty three children were subjected to a screening procedure that consisted of an ear, nose and throat examination, impedance and pure tone screening tests. The results suggested that 15,2\% of the population had ear and/or hearing pathology. This pathology ranged from middle ear conditions $(13,4 \%)$ to sensory neural conditions $(1,8 \%)$. From these results it appears that the incidence of ear and hearing problems in this population is relatively low. This confirms previous research that states the good health conditions of this community.

Die verskeidenheid van etniese groepe in Suidelike Afrika bied 'n unieke geleentheid vir die bestudering van siektetoestande byvoorbeeld oor- en gehoorpatologieë wat geassosieer word met die lewenstyl en omgewing (Van Staden, 1983).

In die verband is 'n stam van ongeveer 1000 persone wat steeds die tradisionele lewenswyse van hul voorvaders behou, in die noordelike dele van die Republiek van Venda geïdentifiseer, in 'n afgeleë gebied wat as Tshikunda-Malema bekend staan (Van Staden, 1983)!

Die algemene gesondheidstoestand van hierdie mense is uitsonderlik goed, veral as die afwesigheid van gereelde mediese dienste in ag geneem word (Breighton 1983, Van Staden, Nel en Van Zyl, 1982). Die persone blyk ongeaffekteer te wees deur siektes wat normaalweg geassosieer word met 'n gesofistikeerde lewenstyl en vesellose dieet, byvoorbeeld hoë bloeddruk en artritis (Van Staden, 1983, Breighton, 1983).

Aangesien dit bekend is dat otitis media 'n hoë voorkoms toon in gebiede waar mediese sorg ontoereikend is en die populasie onbewus is van die implikasies van die toestand (Northern en Downs, 1984), ontstaan die vraag of dit ook die geval by hierdie Vendastam is.

'n Ondersoek na die voorkoms en aard van oor- en gehoorpatologie is veral van belang as in gedagte gehou word dat selfs ' $n$ geringe tydelike gehoorverlies, soms deur otitis media veroorsaak kan word. Hierdie gehoorverlies kan 'n negatiewe effek op die ontwikkeling van kommunikasie- en akademiesevermoëns uitoefen (Howie, 1977, Downs, 1977), en dus 'n verminderde lewenskwaliteit tot gevolg hê. Verder kan die resultate van so 'n studie 'n belangrike bydrae lewer in die daarstelling van ' $n$ basislyn van die voorkoms van oor- en gehoorprobleme wat latere navorsers as verwysing kan gebruik (Van Staden, 1982). Dit is veral ook van belang in die geval van Tshikunda-Malema se inwoners wat waarskynlik veranderinge in lewenstyl en eetgewoontes sal vertoon as gevolg van die moontlikheid van ontwikkeling van sekondêre industrieë in die toekoms van die gebied (Breighton 1983).

'n Moontlike uitvloeisel van die resultate is die inisiëring van 'n gehoorkonserveringsprogram wat deur die lede van die gemeenskap self in stand gehou kan word.

\section{METODE}

Vir die doel van hierdie studie is kinders geselekteer wat in die Tshikunda-Malemagebied van Venda woonagtig is. Elke kind is aan 'n oor-, neus- en keelondersoek sowel as 'n suiwertoon- en impedanssiftingstoets onderwerp. Deur hierdie drie prosedures te gebruik word effektiewe identifikasie van oor- en gehoorprobleme verhoog (Fisch, 1981).

\section{PROEFPERSONE}

Kinders tussen die ouderdom van een en twaalf jaar is getoets omdat die grootste frekwensie van oor- en gehoorpatologie voor die ouderdom van 12 jaar voorkom. Kinders in hierdie ouderdomsgroep wat vrywillig by ' $n$ gesondheidskliniek aangemeld het, is aan die siftingsprogram onderwerp. Deur konkrete beloning is gepoog om soveel as moontlik kinders te motiveer om vir toetsing aan te meld. Honderd drie-en-vyftig kinders is gevolglik getoets. In Tabel 1 word die proefpersone in terme van geslag en ouderdom voorgestel.

\section{Apparaat}

Die apparaat wat vir die oor-, neus- en keelondersoek gebruik is, is standaardapparaat, byvoorbeeld ' $n$ koplig, neusspekulum en otoskoop. 
Tabel 1 Voorstelling van proefpersone

\begin{tabular}{|c|c|c|c|}
\hline Ouderdom & Manlik & Vroulik & Totaal \\
\hline l & 1 & 6 & 7 \\
\hline 2 & 2 & 1 & 3 \\
\hline 3 & 2 & 6 & 8 \\
\hline 4 & 4 & 6 & 10 \\
\hline 5 & 9 & 5 & 14 \\
\hline 6 & 8 & 10 & 18 \\
\hline 7 & 11 & 6 & 17 \\
\hline 8 & 7 & 9 & 16 \\
\hline 9 & 3 & 13 & 16 \\
\hline 10 & 10 & 8 & 18 \\
\hline 11 & 9 & 9 & 18 \\
\hline 12 & 5 & 3 & 8 \\
\hline Totaal & 71 & 82 & 153 \\
\hline
\end{tabular}

Die apparaat wat in die gehoorsiftingsprosedure gebruik is, is 'n Madsen model TBN 60 - suiwertoonoudiometer. Die oudiometer is volgens ISO 1964 standaarde geyk en daagliks tydens gebruik psigo-akoesties geyk. Die impedansoudiometriese siftingsprosedures is deur middel van 'n Damplex D175 impedansmeter uitgevoer. Die elektriese voorsiening is van 'n kragopwekker verkry.

Vir pedo-oudiometriese toetsing van kinders wat nie deur middel van die suiwertoonsiftingsprosedure getoets kon word nie, is van 'n Zenith Neometer en geykte geraasmakers gebruik gemaak.

\section{Toetsomgewing}

Klankdigte fasiliteite was nie vir suiwertoonsiftingsoudiometrie beskikbaar nie. 'n Vertrek, weg van die kliniek-aktiwiteite, is vir die doel geselekteer. Die vertrek was bevredigend vir siftingsdoeleindes.

\section{Toetsafnemers}

Oudiometriese toetsing is deur 'n volledige oor-, neus- en keelondersoek deur 'n oor-, neus- en keelarts voorafgegaan. Daarna is oudiometriesesiftingsprosedures, volgens ' $n$ voorafbepaalde prosedure, deur twee ervare oudioloë uitgevoer. As gevolg van die taalprobleem is daar van 'n tolk gebruik gemaak vir die gee van instruksies en verkryging van die gevalsgeskiedenis.

\section{PROSEDURE}

\section{Dataversameling}

Elke proefpersoon wat vir toetsing aangemeld het, het die volgende prosedure deurloop:

- 'n tolk verkry inligting ten opsigte van 'n geskiedenis van ooren gehoorprobleme van die ouers. In die geval van die ouer kinders, is die inligting van die kind self, verkry.

- hierna ondergaan die kind 'n oor-, neus- en keelondersoek. Oorwas word verwyder sodat impedansoudiometrie suksesvol uitgevoer kan word. Die otoskopiese bevindinge word aangeteken.

- die proefpersoon ondergaan dan 'n impedansoudiometriese ondersoek. Hierdie toetsing sluit in timpanometrie, meting van statiese compliance en akoestiese reflekse.

- hierna volg die suiwertoonsiftingstoets. Indien die kind te jonk is vir suksesvolle kondisionering vir die uitvoering van die suiwertoontoets, is van gedragsobservering met aanbieding van geraasmakers, gebruik gemaak.

\section{Dataverwerking}

Vir die verwerking van die rou data is die toets- en ondersoekgegewens wat by elke kind verkry is, afsonderlik in tabelvorm uiteenge- sit. Die gehoor is as normaal beskou indien die proefpersoon response gelewer het by $500 \mathrm{~Hz}, 1 \mathrm{kHz}$ en $2 \mathrm{kHz}$ by $20 \mathrm{~dB}$ GP en $25 \mathrm{~dB}$ GP by $4 \mathrm{kHz}$ (Northern en Downs, 1984). Die proefpersoon slaag dus die suiwertoonsiftingstoets by hierdie drempelwaardes. Gedragsobservering daarenteen, was subjektief van aard. Die baba moes bevredigende lokaliseringsresponse op stimuli lewer (Northern en Downs 1984).

In die geval van impedansoudiometrie, slaag die proefpersoon die siftingstoets indien ' $n$ tipe A-timpanogram en 'n refleks by $105 \mathrm{~dB}$ GP of laer verkry word (Harford et al. 1978).

Vir die klassifikasie van die resultate van proefpersone met sereuse otitis media, is van die prosedure van Cantekin (1983) gebruik gemaak. Akute otitis media en chroniese otitis media is deur die oor-, neus- en keelarts gediagnoseer.

\section{RESULTATE EN BESPREKING}

Van die 153 kinders (306 ore) wat getoets is, kon 15 kinders (30 ore) nie suksesvol deur middel van die suiwertoon- en impedansoudiometriese prosedures getoets word nie, (Tabel 2). 'n Totaal van 138 proefpersone ( 276 ore) is dus suksesvol deur middel van albei toetsprosedures getoets.

Tabel 2 Kinders wat nie suksesvol deur middel van die toetsprosedures getoets kon word nie

\begin{tabular}{|c|c|c|c|}
\hline \multirow{2}{*}{ Ouderdom } & \multirow{2}{*}{ Aantal } & \multicolumn{2}{|c|}{ Nie getoets deur middel van } \\
\cline { 3 - 4 } & & Impedans & Suiwertoon \\
\hline $1-3 \mathrm{jr}$ & 9 & 2 & 9 \\
\hline $4-12 \mathrm{jr}$ & 6 & 2 & 6 \\
\hline Totaal & 15 & 4 & 15 \\
\hline
\end{tabular}

Soos verwag kan word was meer kinders in die jonger ouderdomsgroep (nege kinders) onsuksesvol getoets, teenoor die vier- tot twaalfjariges waar ses nie suksesvol getoets kon word nie. Dit is verder ook belangrik om op te merk dat geen een van dié kinders deur middel van die suiwertoontoets toetsbaar was nie, maar dat 'n oordeel ten opsigte van middeloorfunksionering wel deur middel van die impedansresultate gemaak kon word. Impedansoudiometriese resultate kan dus ' $n$ bydrae lewer wanneer geen samewerking vir suiwertoontoetsprosedures verkry kan word nie. (Northern 1978).

Uit die resultate blyk dit duidelik dat met toename in ouderdom daar 'n geleidelike styging in die persentasie van normale oudiometriese resultate is. Daar is egter ' $n$ enkele uitsondering naamlik die sewejariges, waar die resultate op ' $n$ afname in normale ooren gehoorfunksionering dui. Dit kan in verband gebring word met Harvey en Wilmot (1969) se bevinding, naamlik dat daar 'n geringe toename van middeloortoestande tussen vier- en negejariges voorkom. Die hoër voorkoms van oor- en gehoorprobleme by hierdie groep word verklaar na aanleiding van die boonste lugweginfeksies wat dikwels op die ouderdom voorkom. Vanaf elfjarige ouderdom is daar opvallend minder afwykende resultate. Dit stem ook ooreen met die resultate van vorige navorsers (Weber, McGovern en Zink, 1967).

VOORKOMS VAN AFWYKENDE SUIWERTOON- EN/OF IMPEDANSSIFTINGSOUDIOMETRIESE RESULTATE-

Waar Figuur 1 'n beeld gee van die voorkoms van resultate wat binne normale perke vir suiwertoon- en impedanssiftingsprosedu- 


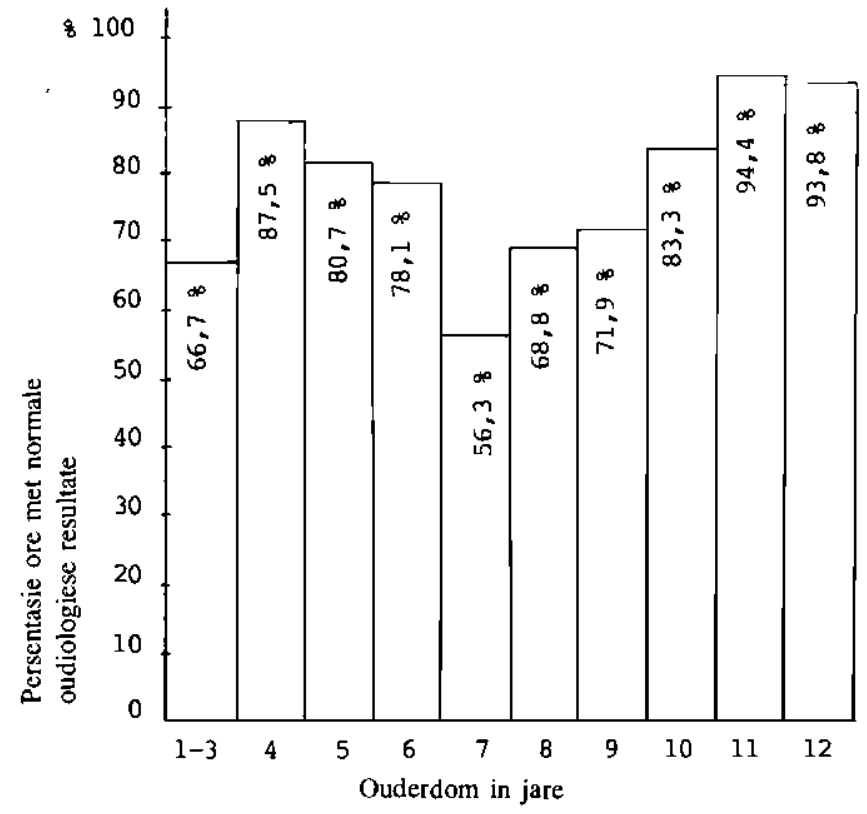

Figuur 1 Voorkoms van normale suiwertoon- en impedansresultate

res is, word die voorkoms van afwykende resultate in Tabel 3 en 4 weergegee. In Tabel 3 word die proefpersone met 'n sensoriesneurale betrokkenheid aangedui, terwyl Tabel 4 die proefpersone met middeloorpatologie weergee.

Tabel 3 Proefpersone wat suiwertoontoetsing faal, maar impedanstoetsing slaag ( 3 kinders)

\begin{tabular}{|c|c|c|c|}
\hline \multirow{2}{*}{$\begin{array}{l}\text { Ouderdom van } \\
\text { elke proef- } \\
\text { persoon }\end{array}$} & \multirow{2}{*}{$\begin{array}{l}\text { Ore met af- } \\
\text { wykende sui- } \\
\text { wertoonre- } \\
\text { sultate }\end{array}$} & \multicolumn{2}{|c|}{$\begin{array}{l}\text { Suiwertoongemiddeld in } \\
\text { afwykende ore in } \mathrm{dB}\end{array}$} \\
\hline & & Links & Regs \\
\hline 3 jaar & 2 & 30 & 30 \\
\hline 8 jaar & 2 & 50 & 65 \\
\hline 12 jaar & 1 & & $\begin{array}{c}25 \\
\text { (hoë frekwensie } \\
\text { verlies) }\end{array}$ \\
\hline $\begin{array}{c}\text { Totaal } \\
\%\end{array}$ & $\begin{array}{l}5 \\
1,8 \%\end{array}$ & & \\
\hline
\end{tabular}

Tabel 4 Die voorkoms van afwykende impedansoudiometriese resultate

\begin{tabular}{|c|c|c|c|c|c|}
\hline \multirow{2}{*}{$\begin{array}{l}\text { Ouderdom } \\
\text { van proef- } \\
\text { persone } \\
\text { in jare }\end{array}$} & \multicolumn{3}{|c|}{ Afwykende resultate } & \multirow[b]{2}{*}{$\begin{array}{c}\text { Ore } \\
\text { getoets }\end{array}$} & \multirow[b]{2}{*}{$\%$} \\
\hline & $\begin{array}{c}\text { Faal ST } \\
\text { Faal Imp }\end{array}$ & $\begin{array}{c}\text { Faal ST } \\
\text { Slaag Imp }\end{array}$ & Aantal & & \\
\hline $1-3$ & 2 & 2 & 4 & 18 & 22,2 \\
\hline 4 & 2 & - & 2 & 16 & 12,5 \\
\hline 5 & 3 & 2 & 5 & 26 & 19,2 \\
\hline 6 & 7 & - & 7 & 32 & 21,9 \\
\hline 7 & 9 & 5 & 14 & 32 & 43,8 \\
\hline 8 & 6 & - & 6 & 32 & 18,8 \\
\hline 9 & 7 & 2 & 9 & 32 & 28,1 \\
\hline 10 & 6 & 2 & 8 & 36 & 22,2 \\
\hline 11 & - & 2 & 2 & 36 & 5,5 \\
\hline 12 & - & - & 0 & 16 & 0 \\
\hline Totaal & 42 & 15 & 57 & 276 & 20,7 \\
\hline
\end{tabular}

ST = stiwerioon

Imp $=$ impedans

Die Suid-Afrikaanse Tydskrif vir Kommunikasieafuykings, Vol. 32, 1985
Uit Tabel 3 is dit dus duidelik dat vyf ore die suiwertoonsiftingstoets gefaal het, maar die impedanssiftingstoets geslaag het. Hierdie resultate impliseer normale middeloorfunksionering maar verminderde gehoorsensitiwiteit wat op 'n sensories-neurale gehoorverlies kan dui.

Die driejarige kind vertoon binouraal suiwertoondrempels van 30 $\mathrm{dB}$ wat op ' $\mathrm{n}$ geringe gehoorverlies dui. Hierdie kind was egter moeilik kondisioneerbaar en die moontlikheid dat hy wel oor normale gehoor beskik, is goed. Die kind het moontlik nie op sy drempel gereageer nie, maar eers op 'n hoër vlak.

Die agtjarige kind vertoon 'n matige binourale gehoorverlies terwyl die twaalfjarige slegs 'n geringe monourale hoë frekwensie gehoorverlies vertoon. 'n Gebrek aan bevredigende agtergrondsinligting maak die oorsake van hierdie gehoorverliese moeilik bepaalbaar.

Uit Tabel 4 blyk dit duidelik dat $20,7 \%$ van die populasie een of ander vorm van middeloorpatologie vertoon, terwyl slegs $1,8 \%$ (Tabel 3) 'n sensories neurale betrokkenheid vertoon. Die hoër voorkoms van middeloorpatologie teenoor sensories-neurale gehoorverliese stem ooreen met vorige navorsing. Hierdie navorsing dui daarop dat meer as sowat $70 \%$ van alle gehoorprobleme, as gevolg van middeloorpatologie, in die skoolgaande populasie voorkom (Harvey en Wilmot, 1969).

Dit is verder opvallend dat meer kinders (42) slegs uitvalle op die impedanstoetsresultate toon, teenoor kinders (15) wat uitval op beide suiwertoon- en impedanstoetsresultate. Hierdie bevinding bevestig die stelling van Brooks (1980) dat 'n beduidende aantal kinders met middeloorpatologie se gehoor as normaal beskou sou word, indien impedansoudiometrie nie deel van die toetsbattery sou wees nie. Vyftien ore vertoon egter uitvalle op beide suiwertoon- en impedansoudiometriese resultate. Hierdie resultate kan op 'n gevorderde middeloorpatologie of 'n gemengde gehoorverlies dui.

Tabel 5 Geslag van kinders met afwykende oudiologiese resultate

\begin{tabular}{|l|c|c|}
\cline { 2 - 3 } \multicolumn{1}{c|}{} & Seuns & Dogters \\
\hline $\begin{array}{l}\text { Aantal met afwykende } \\
\text { toetsresultate }\end{array}$ & 20 & 20 \\
\hline $\begin{array}{l}\text { Totale aantal } \\
\text { kinders getoets }\end{array}$ & 67 & 71 \\
\hline$\%$ & $\begin{array}{c}30 \\
(29,9 \%)\end{array}$ & $\begin{array}{c}28 \\
(28,2 \%)\end{array}$ \\
\hline
\end{tabular}

Tabel 6 Die aard van oor- en gehoorpatologie

\begin{tabular}{|c|c|c|}
\hline Diagnose & $\begin{array}{l}\text { Aantal uit } \\
276 \text { ore } \\
\text { getoets }\end{array}$ & Persentasie \\
\hline \multirow{4}{*}{$\begin{array}{l}\text { Middeloorpatologie: } \\
\text { sereuse otitis media } \\
\text { akute otitis media } \\
\text { Chroniese otitis media } \\
\quad \text { - perforasies } \\
\text { - cholestiatoom } \\
\text { Subtotaal } \\
\text { Sensories-Neurale patologie } \\
\text { Subtotaal }\end{array}$} & $\begin{array}{r}29 \\
2\end{array}$ & $\begin{array}{r}10,5 \\
0,7\end{array}$ \\
\hline & $\begin{array}{l}5 \\
1\end{array}$ & $\begin{array}{l}1,8 \\
0,4\end{array}$ \\
\hline & 37 & 13,4 \\
\hline & 5 & 1,8 \\
\hline Totaal & 42 & 15,2 \\
\hline
\end{tabular}


Uit Tabel 5 blyk dit dat feitlik ewe veel seuns $(29,9 \%)$ as dogters $(28,2 \%)$ afwykende oudiologiese toetsresultate vertoon. Hierdie resultate stem dus nie ooreen met die navorsing van Klein (1978) wat bevind het dat spesifiek otitis media, betekenisvol meer by seuns as dogters voorkom nie.

\section{AARD VAN DIE OOR- EN GEHOORPROBLEME}

Alhoewel die inligting uit Tabelle 2 en 3 aandui dat 62 ore as afwykend beskou word, dui Tabel 6 daarop dat slegs 42 ore gehoorpatologie vertoon. Dit kan verklaar word aan die hand van die wyse waarop die groep met sereuse otitis media geklassifiseer is, na aanleiding van die voorstel van Cantekin (1983). Daar is dus van beide die otoskopiese ondersoek en impedanstoetsresultate in Tabel 6 gebruik gemaak. Die resultate in Tabel 3 is slegs op grond van die impedanstoetsresultate saamgestel.

Die beskikbare data is geklassifiseer deur die slaag /faal-kriteria van die impedans en otoskopiese ondersoeke met mekaar in verband te bring (Cantekin 1983). Sodoende kon sereuse otitis media geïdentifiseer word. Suiwertoon- en impedanstoetsresultate is saam met die otoskopiese ondersoek gebruik vir identifikasie van sensories-neurale gehoorverliese. In die geval van akute otitis media, perforasies en cholestiatome is daar hoofsaaklik op die otoskopiese ondersoek staatgemaak.

Uit Tabel 6 blyk dit duidelik dat $15,2 \%$ van die Venda-kinders wat getoets is, oor- of gehoorpatologie vertoon. Middeloorpatologie kom voor by $13,4 \%$ van die getoetste kinders. Hierdie persentasie is opvallend laag wanneer dit met die hoër voorkoms van middeloorpatologie onder ander etniese kindergroepe vergelyk word. Aangehaal uit Corth en Harris (1984) is die voorkoms van middeloorpatologie onder getoetste populasies: Alaska $27 \%$, Eskimo $15 \%$, Indo-Chinese vlugtelingkinders $68,8 \%$.

Die voorkoms van slegs perforasies onder Navajo-skoolkinders was $14 \%$, Eskimo-kinders 32\%, Alaskaanse kinders $17 \%$ en Amerikaans-Indiaanse kinders 6,5\% (Northern 1978, Howie 1977, Johnson en Watrous 1978). Slegs 1,8\% van die getoetste Vendakinders toon perforasies.

Die voorkoms van sereuse otitis media by die Venda-kinders $(10,5 \%)$ is ook heelwat laer as die $20,5 \%$ van die Amerikaanse Indiane (Johnson en Watrous 1978).

Dit is verder nodig om in gedagte te hou dat hierdie studie tydens Venda se wintermaande uitgevoer is. Die moontlikheid bestaan dus dat die voorkoms van oor- en gehoorprobleme $(15,2 \%)$ kan afneem indien die toetse in die somermaande herhaal word (Klein 1978).

Opsommend wil dit dus voorkom asof die voorkoms van oor- en gehoorprobleme by hierdie groep Venda-kinders laag is. Die stam kan dus nie as 'n hoë risiko-groep vir oor- en gehoor-patologie beskou word nie.

\section{GEVOLGTREKKING}

Verskeie faktore wat bydraend is tot ' $n$ hoë voorkoms van middeloorpatologie is al geïdentifiseer byvoorbeeld onder andere sosioekonomiese status, behuising, voeding, stedelike en landelike omgewing, klimaat, gebrek aan mediese dienste (Klein 1978, Corth en Harris 1984).

Die verklaring van die hoë voorkoms van otitis media by die inheemse Noord-Amerikaanse bevolkingsgroepe word hoofsaaklik aan die lae sosio-ekonomiese status en faktore wat hiermee verband hou, toegeskryf (Klein, 1978),
In die geval van die Venda-kinders is die sosio-ekonomiese status laag, (Van Nieuwenhuizen en Oosthuizen, 1984), maar ten spyte daarvan is die Vendas, soos reeds genoem, baie gesond (Van Staden, 1983). Daar kan dus verwag word dat die voorkoms van ooren gehoorprobleme laag sal wees.

Dit is egter moontlik dat 'n lae sosio-ekonomiese status, soos deur 'n Westerse industriële gemeenskap beoordeel, nie op die tradisionele lewenswyse van die Venda van toepassing gemaak kan word nie. Geld speel 'n relatief onbelangrike rol en hierdie mense is tot 'n groot mate selfonderhoudend, en afhanklik van die natuur vir hul daaglikse voedselbehoeftes.

Behuising in lae sosio-ekonomiese groepe is dikwels beknop en ontoereikend (Klein, 1978). Dit blyk egter nie die geval by die Venda te wees nie. Behuising is 'n hut wat van hout, klei en dekgras gebou is. Die man woon in sy eie hut, terwyl die vrou en haar kinders (gemiddeld drie kinders) hul eie hut bewoon (Van Staden, Nel en Van Zyl, 1982).

Voeding is ' $n$ verdere faktor wat die voorkoms van middeloorprobleme verhoog. Kinders wat geborsvoed word vertoon 'n laer insidensie van middeloorprobleme (Klein 1978). Volgens Crous (1984) word die Venda kind dikwels tot op twee jaar of selfs langer geborsvoed. Hierdie faktor mag dus bydraend tot die relatief lae voorkoms van oor- en gehoorprobleme wees.

Die feit dat die persone in 'n landelike omgewing woonagtig is, (Klein, 1978) en die klimaat deur die jaar gunstig is, (temperatuur is nie laer as gemiddeld $15^{\circ} \mathrm{C}$ nie) (Van Nieuwenhuizen en Oosthuizen, 1984) dra waarskynlik by tot die Venda se goeie algemene gesondheid, en dus die relatief lae voorkoms van oor- en gehoorprobleme.

Westerse mediese dienste, blyk onvoldoende te wees aangesien die Venda-gebied slegs drie tot vier keer per jaar deur mediese spanne besoek word. Hierdie afgeleë groep mense vertoon nogtans goeie algemene gesondheid en die voorkoms van oor- en gehoorprobleme is waarskynlik om die rede ook laer as wat verwag sou word. 'n Hoër voorkoms is verwag, as navorsing wat met inheemse Amerikaanse rassegroepe gedoen is, in ag geneem word (Johnson en Watrous 1978).

Die lewenstyl en eetgewoontes van die inwoners van TshikúndaMalema sal waarskynlik in die toekoms, as gevolg van Westerse invloede, verander. Dit is van belang dat die invloed van die verandering op die aard en voorkoms van oor- en gehoorpatologie, met die oog op 'n gehoorkonserveringsprogram gemonitor word.

\section{AANBEVELINGS VIR VERDERE NAVORSING}

'n Vergelykende studie waar die voorkoms van oor- en gehoorprobleme van die landelike Venda-kind met die voorkoms van ooren gehoorprobleme onder die stedelike swart kind vergelyk word.

Bepaling van voorkoms van oor- en gehoorprobleme onder die volwassenes van Tshikunda-Malema. Die voorkoms van ouderdomsdoofheid kan bepaal word.

\section{BEDANKING}

Die skrywers bedank die Hans Snijkers Instituut vir die geleentheid wat daargestel is om hierdie navorsing te kon doen.

The South African Journal of Communication Disorders, Vol. 32, 1985 


\section{VERWYSINGS}

Breighton, S. Third World Rheumatology, In Carson Dick, W. en Moll, J.M.H. (eds) Recent Advances in Rheumatology $\mathrm{nr}$ (3). Edinburg; Churchill-Livingstone, 1983.

Brooks, D.N. Impedance Screening. In Jerger, J., Northern, J.L. Clinical Impedance Audiometry (tweede uitgawe). Massachusetts: American Electromedics Corporation, 1980.

Cantekin, E.I. Algorithm for diagnosis of otitis media with effusion. In Stool, S.E. en Bluestone, C.D. (eds) Studies in otitis media Pittsburgh Otitis Media Research Centre, Progress Report. 92, 6, 1983.

Corth, S.B. en Harris, R.W. Incidence of Middle Ear Disease in Indochinese Refugee School Children. Audiology, 23, 27-37, 1984.

Crous, J.M. Lektrise, Departement Huishoudkunde en Dieëtkunde. Persoonlike mededeling, 1984.

Downs, M. The expanding Imperatives of Early Identification. In Bess, F.H. Childhood Deafness: Causation, Assessment and Management. New York: Grune \& Stratton, 1977.

Fisch, L. Development of School Screening Audiometry Brit. J. Audiology, 15, 87-95, 1981.

Harford, E., Fox, J., Clemis, J. Impedance Audiometry for Identification of Conductive component in School Children. In Harford, E.R., Bess, F.H., Bluestone, C.D., Klein, J.O. (eds) Impedance Screening for Middle Ear Disease in Children. New York: Grune \& Stratton, 1978.

Harvey, R.M. en Wilmot, T.J. The Incidence of Deafness in Childhood. J. Lanyngology Otology, 83, 449-456, 1969.

Howie, V.M. Acute and recurrent acute otitis media. In Jaffe, B.F. (ed) Hearing Loss in Children. Baltimore: University Park Press, 1977.
Johnson, J.S., Watrous, B.S. An Acoustic Impedance Screening program with an American Indian population. In Harford, E.R., Bess, F.H., Bluestone, C.D., Klein, J.O. (eds), Impedance Screening for Middle Ear Disease in Children. New York: Gune \& Stratton, 1978.

Klein, J.O. Epidemiology of Otitis Media. In Harford, E.R., Bess, F.H., Bluestone, C.D., Klein, J.O. (eds) Impedance Screening for Middle Ear Disease in Children. New York: Grune \& Stratton, 1978.

Northern, J.L. Impedance Screening in Special Populations - State of the Art. In Harford, E.R., Bess, F.H., Bluestone, C.D., Klein, J.O. (eds). Impedance Screening for Middle Ear Disease in Children. New York: Grune \& Stratton, 1978.

Northern, J. en Downs, M. Hearing in Children (derde uitgawe) Baltimore: Williams \& Wilkins, 1984.

Van Nieuwenhuizen, E.F.J. en Oosthuizen, J.S. Sosio-ekonomiese opname in Tshikunda-Malema (Venda) - 'n Tussentydse verslag. Universiteit van Pretoria: Instituut vir Bedryfs- en Ontwikkelingsosiologie. Departement Sosiologie, 1984.

Van Staden, D.A. Kennismaking met Tshikunda-Malema Geneeskunde, 1, 37-39, 1982.

Van Staden, D.A. Health and disease in a traditional-living tribe in Southern Africa. Ecology of Disease, 2, 149-150, 1983.

Van Staden, D.A., Nel, W., Van Zyl, M.L. Groep A B-hemolitiese streptokokke in 'n tradisionele Swart gemeenskap. S.A. Med. J., 62, 569-570, 1982.

Weber, H.J., McGovern, F.J., Zink, D. An Evaluation of 1000 Children with hearing loss. J. Speech Hear. Disord., 32, 343-354, 1967. 


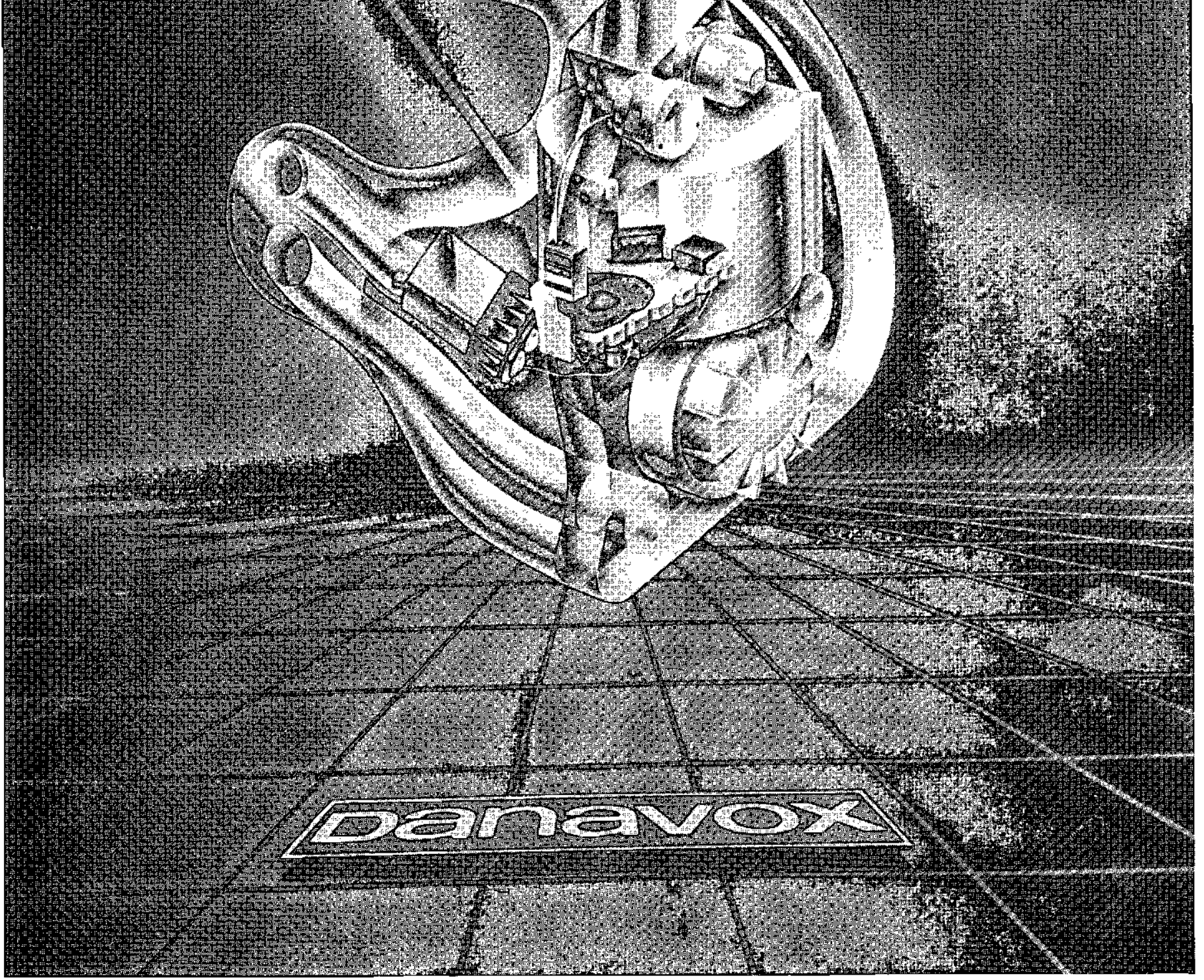

The South African Journal of Communication Disorders, Vol. 32, 1985 